\title{
DESCOBRINDO ENFERMAGEM EXPERIMENTANDO SER ENFERMEIRO
}

\author{
Paulo Alexandre Oliveira Marques ${ }^{1}$
}

\begin{abstract}
RESUMO: Atividade desenvolvida em 2011 no âmbito do Programa Nacional de Iniciação ao Ambiente Universitário para os estudantes do ensino secundário, em Portugal, promovido pela Universidade do Porto, em parceria com a Escola Superior de Enfermagem do Porto - Portugal. Os estudantes foram desafiados a experimentar um conjunto de procedimentos de enfermagem e a trabalhar num conceito de enfermagem. Durante uma semana os estudantes vivenciaram o ambiente da Escola de Enfermagem, participaram em aulas teóricas, teórico-práticas e práticas, em contexto laboratorial, para construírem e apresentarem sua perspectiva do que é ser enfermeiro. A experiência revelou-se positiva, segundo os participantes, contribuindo para a formação de uma ideia crítico-reflexiva acerca do curso de graduação e da Enfermagem, auxiliando-os na clarificação de percepções e na definição da sua orientação vocacional, além de otimizar a convivência com estudantes do ensino superior, o que se revelou uma oportunidade de amadurecimento.
\end{abstract}

DESCRITORES: Educação em enfermagem; Educação superior; Orientação vocacional.

\section{DISCOVERING NURSING THROUGH TRYING OUT BEING A NURSE}

ABSTRACT: This activity was carried out in 2011 in the framework of the National Program for Initiation to the University Environment for secondary school pupils, in Portugal, promoted by the University of Porto, in partnership with the Porto Nursing College - Portugal. The students were challenged to try a set of nursing procedures and to work in a nursing concept. For one week the students experienced the atmosphere of the School of Nursing, participated in theory classes, and theory-practice and practice classes in a laboratory context, so as to construct and present their perspective on what it is to be a nurse. The experience was shown to be positive, according to the participants, contributing to the formation of a critical-reflexive idea regarding the undergraduate Nursing course, helping them to clarify their perceptions and define their vocational orientation, as well as to optimize the co-existence with the higher education students, which was shown to be an opportunity to mature.

DESCRIPTORS: Nursing education; Higher education; Vocational orientation.

\section{DESCUBRIENDO ENFERMERÍA EXPERIMENTANDO SER ENFERMERO}

RESUMEN: Actividad desarrollada en 2011 en el ámbito del Programa Nacional de Iniciación al Ambiente Universitario para los estudiantes de la enseñanza secundaria, en Portugal, promovido por la Universidad de Porto, en colaboración con la Escuela Superior de Enfermería de Porto - Portugal. Los estudiantes fueron desafiados a experimentar un conjunto de procedimientos de enfermería y a trabajar en un concepto de enfermería. Durante una semana, los estudiantes vivieron el ambiente de la Escuela de Enfermería, participaron en clases teóricas, teórico-prácticas y prácticas, en contexto laboratorial, para construir y presentar su perspectiva de lo que es ser enfermero. La experiencia se ha revelado positiva, de acuerdo a los participantes, contribuyendo para la formación de una idea crítico reflexiva acerca del curso de graduación y de la Enfermería, auxiliándolos en el esclarecimiento de percepciones y en la definición de su orientación vocacional, además de otimizar la convivencia con estudiantes de la enseñanza superior, lo que se ha revelado una oportunidad de maduración. DESCRIPTORES: Educación en enfermería; Enseñanza superior; Orientación vocacional.

${ }^{1}$ Enfermeiro. Doutor em Enfermagem. Professor da Escola Superior de Enfermagem do Porto-Portugal. Coordenador do Programa 'Try to be a nurse. It's cool!!' 


\section{INTRODUÇÃO}

No tempo atual, a opção por um determinado caminho universitário, que se coloca a milhares de jovens que terminam o ensino secundário, não é uma tarefa fácil. Por um lado, nem sempre há uma tendência definida, podendo levar à desistências ou opções aleatórias que podem ter consequências negativas no futuro $^{(1)}$. Por outro lado, quando existe um interesse específico, a relação entre o que se pensa e a realidade de cada curso pode constituir uma situação frustrante, levando a que se decida com base em dados que se supõem e que nem sempre correspondem à realidade. Esse fato gera desilusões e desistências, com repercussões na vinculação e no timing de entrada no mundo laboral.

Consciente dessas questões e à semelhança do que já vem sendo feito por outras universidades europeias ${ }^{(2)}$, a Universidade do Porto (UP) criou o Programa Universidade Júnior (U.Jr.) $)^{(3)}$. O programa tem o propósito de permitir aos jovens que anseiam optar por um curso superior, experiências diversas, proporcionadas pelas diferentes áreas do saber e corporizadas pelas Faculdades englobadas na respectiva Universidade, ou por instituições que representem uma mais-valia ímpar, como é o caso da Escola Superior de Enfermagem do Porto (ESEP). Esta é uma Escola com méritos firmados a diversos níveis, do ensino à investigação, nacional e internacionalmente ${ }^{(4)}$.

Um conjunto de circunstâncias, entre as quais a ausência de um Projeto de Enfermagem no seio da U.Jr., a vontade da ESEP na sua elaboração e implementação, e a pronta disponibilidade para o estabelecimento de uma parceria com a UP, permitiram que em 2011 a sétima edição do projeto contasse com o Programa Try to be a nurse. It's cool!', com a participação de jovens numa semana de atividades. A primeira edição do Programa realizou-se em três períodos de uma semana, durante o mês de julho, e contou com a participação de professores da ESEP, responsáveis pelos conteúdos ministrados, bem como com a colaboração de dois monitores (um para cada grupo de sete estudantes do ensino secundário, num total de quarenta e um), selecionados entre estudantes da última etapa do Curso de Licenciatura em Enfermagem (CLE) da ESEP ${ }^{(5)}$.

\section{PROPOSTA PEDAGÓGICA}

A proposta apresentada observou, essencialmente, três critérios: em primeiro lugar, era fundamental seu componente prático, do fazer. É bem verdade que a Enfermagem da prestação de cuidados engloba uma forte dimensão prática e o CLE da ESEP conta com cerca de $50 \%$ dessas. Mas, havia que contar com as expectativas que se supunham serem as dos estudantes, à semelhança do que revelava na experiência de outras atividades inseridas em edições anteriores da U.Jr. Em segundo lugar, o seu conteúdo teria de ser, necessariamente, atrativo, até porque, mais que cativar os estudantes para o curso, a intenção principal passava por imprimir uma imagem positiva da Enfermagem, da instituição e das pessoas. E, finalmente, pretendia-se uma abordagem ao longo da vida, englobando a assistência de enfermagem do nascer ao morrer.

A planificação das atividades teve como suporte a construção de grandes temáticas para os diferentes dias, a saber: a) nasceu uma vida; b) saber para aplicar; c) vamos ser jovens in(formados); d) educar para a saúde; e e) descobrir a missão da Enfermagem no mundo. Esse que, por considerar evidente a ideia de uma dada Enfermagem pré-concebida e, de certa forma, desatualizada ${ }^{(6)}$, relativamente ao que são hoje as competênciasdo enfermeiro de cuidados gerais, em Portugal $^{(7)}$, e que fazia sentido explorar.

\section{IMPLEMENTAÇÃO}

Durante uma semana, os diferentes grupos foram integrados na ESEP, conheceram suas instalações, com destaque para os laboratórios de simulação de procedimentos, e visitaram o museu, porque o presente e o futuro não se fazem sem o revisitar da história. Logo de início, foi-lhes apresentada a proposta de trabalho que desenvolveram em grupo, sobre o que era ser enfermeiro, para iniciarem a reflexão e consequente pesquisa, ao mesmo tempo que assistiam a uma pequena abordagem sobre o assunto.

As ações práticas eram precedidas de uma introdução teórica complementada por demonstração pelos professores, após o que os estudantes eram estimulados à sua realização, sempre com a colaboração e orientação dos monitores. Os estudantes de enfermagem (monitores) desempenhavam um papel crucial e, nessa medida, foram incentivados a descrever em Diário de Campo as suas impressões. Essas, englobando depoimentos dos estudantes, por forma a uma avaliação atempada e completa, que permitisse uma reorientação do percurso, em caso de necessidade. 


\section{AVALIAÇÃO}

No final do programa, foi solicitado aos estudantes o preenchimento de um questionário de avaliação parcial e global do Programa, com 8 perguntas fechadas utilizando uma escala de likert (5 pontos) operacionalizando as variáveis através de dois extremos semânticos (1 correspondendo a score mais favorável e 5 a score mais desfavorável), e também perguntas abertas que, juntamente com os diários e a opinião dos professores, conduziram à apreciação da qualidade e da satisfação dos estudantes.

Os estudantes demonstraram grande maturidade na abordagem das diferentes temáticas, abertura na discussão e confronto de ideias. Também externavam curiosidade na descoberta da Enfermagem e do que fazem os enfermeiros, mesmo que alguns deles não estivessem, necessariamente, a ponderar na hipótese de seguirem esta direção profissional no futuro.

A avaliação realizada pelos estudantes em cada momento, mas sobretudo no final, validou a excelência dessa experiência, $100 \%$ de respostas com score entre 1 e 2 ; desde pessoas aos conteúdos e forma do programa proposto. Apenas dois itens de resposta obtiveram avaliação intermédia (score 3) por cerca de 14\% dos participantes, enquanto a realização do trabalho de grupo intitulado 'descobrir a missão da enfermagem no mundo' obteve $29,2 \%$ de atribuição nesse. Os demais itens obtiveram, quase na totalidade das respostas, scores favoráveis. Valorizaram a aplicabilidade prática das temáticas, os aspetos relacionais e lúdicos desenvolvidos, num ambiente que se proporcionou para tal.

Destaca-se a proposta de inclusão de novas matérias, e ainda o interesse numa visita a uma instituição hospitalar. Finalmente, a totalidade dos estudantes que frequentaram as três atividades revelaram, com grande certeza, que recomendariam o Programa aos seus conhecidos. Assinala-se a constatação de evolução nas significações do que é a Enfermagem e do que é ser enfermeiro.

\section{CONSIDERAÇÕES FINAIS}

A atividade Try to be a nurse. It's cool! revelou-se importante no contexto de um projeto que pretende levar os jovens a uma maior qualificação, à opção por um curso e instituição que sejam do seu agrado. Entre outros fatores, veio ocupar uma lacuna, já que é grande a procura pela formação em Enfermagem, sendo os enfermeiros o maior grupo profissional da saúde, em Portugal.
A informação, em pleno século XXI, é um direito que assiste qualquer cidadão, permitindo-lhe decidir com base segura acerca dos seus interesses e, nessa medida, os programas inseridos na U.Jr. são uma mais-valia para os jovens, permitindo-lhes experimentar in loco, diferentes alternativas, e a potenciar suas qualidades e interesses, ajudando-os nesta importante decisão.

Foi igualmente interessante a adaptação dos professores a um modelo de ensino e aprendizagem em que estão pouco habituados, sem a exigência que é colocada na graduação e sem a respectiva avaliação, bem como, entregue preferencialmente a monitores.

Em 2012, o Programa foi aperfeiçoado, incorporando as recomendações, sobretudo dos estudantes, mas a médio e longo prazo, será interessante verificar se existe correspondência, e em que percentagem, no estudantes admitidos no CLE na ESEP e aqueles que frequentaram esta atividade.

\section{REFERÊNCIAS}

1. Barlem JGT, Lunardi VL, Bordignon SS, Barlem ELD, Lunardi Filho WD, Silveira RS, et al. Opção e evasão de um curso de graduação em enfermagem: percepção de estudantes evadidos. Rev Gaúcha Enferm. 2012;33(2):132-38.

2. European Children's Universities Network [Internet]. [acesso em 22 mar 2012]. Disponível: http://sites.google. com/site/eucunetevents/

3. Universidade Júnior [Internet]. Porto: Universidade do Porto. [acesso em 2 mar 2012]. Disponível: http:// universidadejunior.up.pt/

4. Escola Superior de Enfermagem do Porto [Internet]. Porto: Escola Superior de Enfermagem do Porto - ESEP. [acesso em 2 mar 2012]. Disponível: http://www.esenf.pt

5. Escola Superior de Enfermagem do Porto (2011). Despacho no 8888/2011, de 5 de julho de 2011. Estrutura Curricular da Licenciatura em Enfermagem. Diário da República, 2 ${ }^{\text {a }}$ Série - no 127 - 5 de julho de 2011: 28228-9. Disponível: http://newsletter.esenf.pt:8080/ newsletter/ficheiros/43/drel.pdf

6. Silva AP. Enfermagem avançada: um sentido para o desenvolvimento da profissão e da disciplina. Servir. 2007;55(1-2):11-20.

7. Ordem dos Enfermeiros. Competências do enfermeiro de cuidados gerais [Internet]. Lisboa: Ordem dos Enfermeiros; 2003[acesso em 2 mar 2012]. [2 telas]. Disponível: http://www.ordemenfermeiros.pt/ publicacoes/Documents/CompetenciasEnfCG.pdf 